\title{
Serum Potassium and Glucose Regulation in the ADDITION-Leicester Screening Study
}

\author{
Patrice Carter, ${ }^{1}$ Danielle H. Bodicoat, ${ }^{1}$ Lauren M. Quinn, ${ }^{2}$ Francesco Zaccardi, \\ David R. Webb, ${ }^{1}$ Kamlesh Khunti, ${ }^{1}$ and Melanie J. Davies ${ }^{1}$ \\ ${ }^{1}$ University of Leicester, Diabetes Research Centre, Leicester Diabetes Centre, Leicester General Hospital, Leicester LE5 4PW, UK \\ ${ }^{2}$ Nuffield Science Bursary, University of Birmingham, Birmingham B15 2TT, UK \\ Correspondence should be addressed to Patrice Carter; pc154@le.ac.uk
}

Received 8 December 2014; Revised 20 February 2015; Accepted 3 March 2015

Academic Editor: Normand G. Boulé

Copyright (C) 2015 Patrice Carter et al. This is an open access article distributed under the Creative Commons Attribution License, which permits unrestricted use, distribution, and reproduction in any medium, provided the original work is properly cited.

Introduction. Previous observational studies have shown conflicting results between plasma $\mathrm{K}^{+}$concentrations and risk of type 2 diabetes. To help clarify the evidence we aimed to determine whether an association existed between serum $\mathrm{K}^{+}$and glucose regulation within a UK multiethnic population. Methods. Participants were recruited as part of the ADDITION Leicester study, a population based screening study. Individuals from primary care between the age of 40 and 75 years if White European or 25 and 75 years if South Asian or Afro Caribbean were recruited. Tests for associations between baseline characteristics and $\mathrm{K}^{+}$quartiles were conducted using linear regression models. Results. Data showed individuals in the lowest $\mathrm{K}^{+}$quartile had significantly greater 2-hour glucose levels $(0.53 \mathrm{mmol} / \mathrm{L}, 95 \% \mathrm{CI}$ : 0.36 to $0.70, P \leq 0.001)$ than those in the highest $\mathrm{K}^{+}$quartile. This estimation did not change with adjustment for potential confounders. Conversely, participants in the lowest $\mathrm{K}^{+}$quartile had a $0.14 \%$ lower $\mathrm{HbAlc}$ ( $95 \%$ $\mathrm{CI}-0.19$ to $-0.10: P \leq 0.001)$ compared to those in the highest $\mathrm{K}^{+}$quartile. Conclusion. This cross-sectional analysis demonstrated that lower $\mathrm{K}^{+}$was associated with greater $2 \mathrm{hr}$ glucose. The data supports the possibility that $\mathrm{K}^{+}$may influence glucose regulation and further research is warranted.

\section{Introduction}

The prevalence of type 2 diabetes (T2DM) is currently estimated to be $8.3 \%$ worldwide and has increased rapidly over past decades [1]. This coincides with changes in lifestyle behaviours including an increased consumption of processed foods and a decreased intake of fruit and vegetables [2]. Fruit and vegetables contain a number of potentially beneficial components, including potassium $\left(\mathrm{K}^{+}\right)$, a major intracellular cation of the body.

Previous observational studies have investigated the relationship between serum $\mathrm{K}^{+}$, glucose regulation, and risk of T2DM $[3,4]$. The Atherosclerosis Risk in the Communities (ARIC) study demonstrated an inverse association between serum $\mathrm{K}^{+}$and fasting insulin levels, and risk of T2DM [5]; this relationship was confirmed in the TOPICS 1 study [4]. However a recent study which investigated $\mathrm{K}^{+}$in individuals with impaired glucose regulation only found a significant relationship in those with established hypertension [6]. To help clarify the evidence we aimed to determine whether an association existed between serum $\mathrm{K}^{+}$and glucose regulation within a UK multiethnic population; this is the first UK study to conduct analysis in a high risk population and thus extends the literature available.

\section{Materials and Methods}

Participants were recruited as part of the ADDITION Leicester study, a population based screening study that formed part of ADDITION-Europe, described in detail elsewhere [7]. All individuals were given a $75 \mathrm{~g}$ oral glucose load after an overnight fast and diagnosis of diabetes was made according to 1999 WHO criteria [8]. Plasma glucose was determined using the hexokinase method (Abbott laboratories, Maidenhead, UK; coefficient of variation (CV) 1.61\%). HbAlc was 
quantified using high performance liquid chromatography on an automated DCCT aligned BioRad aligned system (BioRad laboratories, Hemel Hempstead, UK; CV < 0.1\%). Serum total, HDL, LDL-cholesterol, and triglycerides were measured by enzymatic methods (Dade Behring Dimension Analyser, Newark, USA). Plasma creatinine was analysed with kinetic colorimetric methods. Serum potassium was measured using a Siemens ADVIA 2400 Clinical Chemistry System (Siemens Health Care, Germany; CV < 1\%). Analyses were conducted in the pathology laboratories of the University Hospitals of Leicester, NHS Trust, UK. Anthropometric measurements were taken by trained staff following standard operating procedures.

The study was conducted according to the guidelines laid down in the Declaration of Helsinki and all procedures involving human subjects were approved by Leicestershire, Rutland, and Northamptonshire research ethics committee. Written informed consent was obtained from all subjects. The study is registered with ISCRCTN http://www.controlledtrials.com (NCT00318032).

\section{Statistical Analysis}

Baseline characteristics were summarised for the whole study population and separately by $\mathrm{K}^{+}$quartiles. Data were checked for normality by visually assessing normality plots. Tests for associations between baseline characteristics and $\mathrm{K}^{+}$ quartiles $(<4.0 \mathrm{mmol} / \mathrm{L}, 4.0-4.2 \mathrm{mmol} / \mathrm{L}, 4.3-4.4 \mathrm{mmol} / \mathrm{L}$, and $\geq 4.5 \mathrm{mmol} / \mathrm{L}$ ) were conducted using linear regression models: (1) unadjusted; (2) adjusted for baseline measures of average systolic and diastolic blood pressure and for Cockcroft-Gault estimated glomerular filtration rate; (3) adjusted for the previous confounders plus ethnicity, sex, age, and BMI. In sensitivity analyses we restricted the estimations in the subset of participants with normal glucose regulation at baseline $(n=5,249)$ and in those who were not taking any blood pressure medication (diuretics/thiazides, ACEinhibitors, beta-blockers, or angiotensin-II receptor antagonists) $(n=5,187)$. Two sided $P$-value of $<0.05$ was considered statistically significant.

\section{Results}

From 6,749 individuals screened for diabetes we excluded those with missing $\mathrm{K}^{+}$data $(n=154)$, those with $\mathrm{K}^{+}$ greater than $5.5 \mathrm{mmol} / \mathrm{L}(n=62)$, and those with renal dysfunction (creatinine level $>1.7 \mathrm{mg} / \mathrm{dL}(150 \mu \mathrm{mol} / \mathrm{L})(n=$ 13), thus leaving 6,520 participants for the analyses. Of these 4,523 (69.4\%) were White European and 1,629 (25.0\%) were South Asian. Baseline characteristics are presented in Table 1 for the whole population and separately by $\mathrm{K}^{+}$quartile. At screening 5,249 (81\%) had normal glucose tolerance, 1,054 (16\%) had impaired glucose regulation, and 205 (3\%) were newly diagnosed with T2DM.

Participants in the lowest $\mathrm{K}^{+}$quartile had significantly greater 2-hour glucose levels than those in the highest $\mathrm{K}^{+}$ quartile $(0.53 \mathrm{mmol} / \mathrm{L}, 95 \%$ confidence interval (CI): 0.36 to $0.70, P \leq 0.001$; Tables 1 and 2). This estimation did not change with adjustment for potential confounders; model (2): $0.49 \mathrm{mmol} / \mathrm{L} ; 95 \% \mathrm{CI}: 0.29$ to $0.63 ; P \leq 0.001$ and model (3): $0.49 \mathrm{mmol} / \mathrm{L} ; 95 \% \mathrm{CI}: 0.33$ to $0.66 ; P \leq 0.001$. Conversely those in the lowest $\mathrm{K}^{+}$quartile had a $0.14 \%$ lower HbAlc (95\% CI: -0.19 to $-0.10: 0 . P \leq 0.001$ ) compared to those in the highest $\mathrm{K}^{+}$quartile; again adjustment for confounders did not alter the association (Table 3). There was no association between $\mathrm{K}^{+}$quartiles and fasting blood glucose in either the unadjusted or the adjusted models (Table 4). Sensitivity analyses restricted to participants with normal glucose regulation and excluding participants taking antihypertensive medication, including thiazides, did not change the results (data not shown).

\section{Discussion}

This cross-sectional analysis of individuals who were screened for T2DM demonstrated that lower $\mathrm{K}^{+}$was associated with greater $2 \mathrm{hr}$ glucose. No associations were observed between fasting plasma glucose and $\mathrm{K}^{+}$. In contrast those with greater $\mathrm{K}^{+}$had higher HbAlc; however, although statistically significantly different, a change of $0.14 \% \mathrm{HbAlc}$ is unlikely to be considered clinically relevant. The discrepancy between findings in $2 \mathrm{hr}$ glucose and HbAlc could likely reflect the greater sensitivity of the $2 \mathrm{hr}$ glucose to insulin secretion; indeed this process is controlled by ATP-sensitive potassium channels [9]. Additional subanalysis solely of those with normal glucose tolerance at baseline further showed that in otherwise healthy individuals low serum $\mathrm{K}^{+}$was associated with greater $2 \mathrm{hr}$ glucose, suggesting that low serum $\mathrm{K}^{+}$may be implicated in the development of impaired glucose regulation. Prospective studies have previously observed that low baseline $\mathrm{K}^{+}$levels are predictive of development of T2DM $[4,5]$. We do not have sufficient prospective data to examine this in our study.

This study provides a unique dataset of subjects from a multiethnic population; we have conducted analysis to account for potential confounding variables and carried out sensitivity analysis to exclude those taking antihypertensive medication which may influence $\mathrm{K}^{+}$concentrations. Nonetheless several limitations should be mentioned; the measurement of $\mathrm{K}^{+}$was from a single blood sample at the baseline visit; however stringent laboratory conditions were in place to ensure the accuracy of samples. Information on dietary $\mathrm{K}^{+}$consumption or the intake of supplements which may include $\mathrm{K}^{+}$was not available. It is also important to note all levels of $\mathrm{K}^{+}$in our study were within normal physiological levels. We excluded those with creatinine levels greater or equal to $1.7 \mathrm{mg} / \mathrm{dL}$, thus attempting to exclude renal impairment as a potentially confounding factor. Indeed the population appears relatively healthy (mean blood pressure of the cohort is within the normal range), and this should be considered when comparing the data to other populations. Finally this study is cross-sectional by design; therefore we cannot determine the direction of association; however available data supports the possibility that $\mathrm{K}^{+}$may influence glucose regulation and further research is warranted. 
TABLE 1: Characteristics of 6520 participants in the ADDITION-Leicester cross-sectional screening study stratified by baseline serum potassium level.

\begin{tabular}{|c|c|c|c|c|c|c|c|c|c|c|c|}
\hline \multirow{3}{*}{ Characteristic } & \multicolumn{11}{|c|}{$\mathrm{K}^{+}$quartile } \\
\hline & \multicolumn{2}{|c|}{$\begin{array}{l}\text { Total Cohort } \\
\qquad(n=6520)\end{array}$} & \multicolumn{2}{|c|}{$\begin{array}{c}<4.0 \mathrm{mmol} / \mathrm{L} \\
(n=1295)\end{array}$} & \multicolumn{2}{|c|}{$\begin{array}{c}4.0-4.2 \mathrm{mmol} / \mathrm{L} \\
(n=1840)\end{array}$} & \multicolumn{2}{|c|}{$\begin{array}{c}4.3-4.4 \mathrm{mmol} / \mathrm{L} \\
(n=1306)\end{array}$} & \multicolumn{2}{|c|}{$\begin{array}{c}\geq 4.5 \mathrm{mmol} / \mathrm{L} \\
\quad(n=2079)\end{array}$} & \multirow[t]{2}{*}{$P$ for trend ${ }^{\mathrm{a}}$} \\
\hline & $N$ & $\%$ & $N$ & $\%$ & $N$ & $\%$ & $N$ & $\%$ & $N$ & $\%$ & \\
\hline Female & 3429 & 52.6 & 710 & 54.8 & 1084 & 58.9 & 692 & 53.0 & 943 & 45.4 & $\leq 0.001$ \\
\hline Diuretics/thiazides & 648 & 9.6 & 258 & 39.8 & 204 & 31.5 & 73 & 11.3 & 112 & 17.3 & 0.192 \\
\hline ACE-inhibitors & 424 & 6.3 & 95 & 22.4 & 97 & 22.9 & 73 & 17.2 & 158 & 37.3 & 0.643 \\
\hline beta-blockers & 619 & 9.2 & 125 & 20.2 & 154 & 24.9 & 113 & 18.3 & 226 & 36.5 & 0.630 \\
\hline \multirow[t]{2}{*}{$\begin{array}{l}\text { Angiotensin-II } \\
\text { receptor antagonists }\end{array}$} & 223 & 3.3 & 58 & 26.0 & 59 & 26.5 & 35 & 15.7 & 70 & 31.4 & 0.542 \\
\hline & Mean & $\mathrm{SD}$ & Mean & $\mathrm{SD}$ & Mean & $\mathrm{SD}$ & Mean & $\mathrm{SD}$ & Mean & $\mathrm{SD}$ & \\
\hline Age (years) & 56.0 & 10.8 & 56.3 & 10.9 & 55.4 & 10.9 & 55.6 & 10.8 & 56.7 & 10.6 & 0.061 \\
\hline $\operatorname{BMI}\left(\mathrm{kg} / \mathrm{m}^{2}\right)$ & 28.1 & 5.0 & 28.0 & 5.2 & 28.0 & 5.1 & 27.9 & 4.7 & 28.2 & 5.0 & 0.317 \\
\hline $\begin{array}{l}\text { Waist circumference } \\
(\mathrm{cm})\end{array}$ & 93.9 & 13.1 & 93.7 & 14.1 & 93.0 & 13.3 & 93.5 & 12.1 & 95.0 & 12.9 & $\leq 0.001$ \\
\hline $\begin{array}{l}\text { Systolic blood } \\
\text { pressure }(\mathrm{mmHg})\end{array}$ & 136.9 & 19.6 & 136.5 & 20.1 & 136.4 & 19.5 & 136.1 & 19.2 & 138.0 & 19.6 & 0.023 \\
\hline $\begin{array}{l}\text { Diastolic blood } \\
\text { pressure }(\mathrm{mmHg})\end{array}$ & 85.4 & 10.6 & 84.9 & 11.0 & 85.3 & 10.5 & 85.0 & 10.3 & 85.9 & 10.6 & 0.022 \\
\hline EGFR & 75.8 & 13.2 & 75.7 & 12.8 & 76.4 & 13.5 & 76.0 & 12.6 & 75.2 & 13.3 & 0.061 \\
\hline $\begin{array}{l}\text { 2-hour glucose } \\
(\mathrm{mmol} / \mathrm{L})\end{array}$ & 6.0 & 2.4 & 6.4 & 2.4 & 6.1 & 2.4 & 5.9 & 2.3 & 5.9 & 2.4 & $\leq 0.001$ \\
\hline $\begin{array}{l}\text { Fasting blood glucose } \\
(\mathrm{mmol} / \mathrm{L})\end{array}$ & 5.2 & 0.9 & 5.2 & 1.0 & 5.2 & 1.0 & 5.2 & 0.8 & 5.2 & 0.8 & 0.483 \\
\hline $\operatorname{HbAlc}(\%)$ & 5.7 & 0.6 & 5.6 & 0.6 & 5.7 & 0.6 & 5.7 & 0.5 & 5.8 & 0.6 & $\leq 0.001$ \\
\hline $\mathrm{K}^{+}(\mathrm{mmol} / \mathrm{L})$ & 4.3 & 0.4 & 3.7 & 0.2 & 4.1 & 0.1 & 4.3 & 0.1 & 4.7 & 0.2 & $\leq 0.001$ \\
\hline
\end{tabular}

${ }^{a} P$ values for trend were estimated using logistic or linear regression and test whether there is a linear trend in the outcome across potassium categories. SD: standard deviation and eGFR: estimated glomerular filtration rate (Cockroft-Gault formula).

TABLE 2: Linear regression to determine the difference in 2-hour glucose across $\mathrm{K}^{+}$quartiles.

\begin{tabular}{|c|c|c|c|c|}
\hline \multirow{2}{*}{ Models } & \multicolumn{4}{|c|}{$\mathrm{K}^{+}$quartiles } \\
\hline & $<4.0 \mathrm{mmol} / \mathrm{L}$ & $4.0-4.2 \mathrm{mmol} / \mathrm{L}$ & $4.3-4.4 \mathrm{mmol} / \mathrm{L}$ & $\geq 4.5 \mathrm{mmol} / \mathrm{L}$ \\
\hline \multirow{2}{*}{ Model $1^{\mathrm{a}}$} & $0.53(0.36$ to 0.70$)$ & $0.20(0.04$ to 0.35$)$ & $-0.02(-0.19$ to 0.15$)$ & \multirow{2}{*}{ Reference } \\
\hline & $P \leq 0.001$ & $P=0.01$ & $P=0.85$ & \\
\hline \multirow{2}{*}{ Model $2^{\mathrm{b}}$} & $0.49(0.29$ to 0.63$)$ & $0.17(0.02$ to 0.32$)$ & $0.02(-0.15$ to 0.19$)$ & \multirow{2}{*}{ Reference } \\
\hline & $P \leq 0.001$ & $P=0.02$ & $P=0.80$ & \\
\hline \multirow{2}{*}{ Model $3^{c}$} & $0.49(0.33$ to 0.66$)$ & $0.22(0.07$ to 0.37$)$ & $0.05(-0.11$ to 0.21$)$ & \multirow{2}{*}{ Reference } \\
\hline & $P \leq 0.001$ & $P=0.003$ & $P=0.53$ & \\
\hline
\end{tabular}

Data reported as difference in 2-hour glucose (95\% confidence intervals).

${ }^{\mathrm{a}}$ Unadjusted.

${ }^{\mathrm{b}}$ Adjusted for baseline measures of average systolic and diastolic blood pressure and for Cockcroft-Gault estimated glomerular filtration rate.

${ }^{\mathrm{c}}$ Adjusted for the confounders in model 2, plus ethnicity, sex, age, and BMI.

\section{Conflict of Interests}

Melanie J. Davies has received funds for research and honoraria for speaking at meetings and has served on Advisory Boards for Lily, Sanofi Aventis, MSD, Novo Nordisk, Janssen, Astra Zeneca, and Boehringer Ingelheim. Kamlesh Khunti has received funds for research and honoraria for speaking at meetings and has served on Advisory Boards for Astra Zeneca, GSK, Lily, Novartis, Pfizer, Servier, Sanofi Aventis, MSD, and Novo Nordisk. David Webb has received a research training fellowship from Novo Nordisk Research Council. Patrice Carter, Danielle H. Bodicoat, Francesco Zaccardi, and Lauren M. Quinn have nothing to declare.

\section{Authors' Contribution}

Melanie J. Davies (Principle investigator) and Kamlesh Khunti designed the study protocol; David Webb was part of the core clinical team running the study. Patrice Carter, 
TABLE 3: Linear regression to determine the difference in HbAlc across $\mathrm{K}^{+}$quartiles.

\begin{tabular}{|c|c|c|c|c|}
\hline \multirow{2}{*}{ Models } & \multicolumn{4}{|c|}{$\mathrm{K}^{+}$quartiles } \\
\hline & $<4.0 \mathrm{mmol} / \mathrm{L}$ & $4.0-4.2 \mathrm{mmol} / \mathrm{L}$ & $4.3-4.4 \mathrm{mmol} / \mathrm{L}$ & $\geq 4.5 \mathrm{mmol} / \mathrm{L}$ \\
\hline \multirow{2}{*}{ Model $1^{\mathrm{a}}$} & $-0.14(-0.19$ to -0.10$)$ & $-0.08(-0.12$ to -0.04$)$ & $-0.05(-0.09$ to -0.006$)$ & \multirow{2}{*}{ Reference } \\
\hline & $P \leq 0.001$ & $P \leq 0.001$ & $P=0.03$ & \\
\hline \multirow{2}{*}{ Model $2^{b}$} & $-0.15(-0.19$ to -0.11$)$ & $-0.08(-0.12$ to -0.04$)$ & $-0.04(-0.08$ to 0.001$)$ & \multirow{2}{*}{ Reference } \\
\hline & $P \leq 0.001$ & $P \leq 0.001$ & $P=0.05$ & \\
\hline \multirow{2}{*}{ Model $3^{c}$} & $-0.13(-0.17$ to -0.09$)$ & $-0.06(-0.10$ to -0.02$)$ & $-0.03(-0.07$ to 0.01$)$ & \multirow{2}{*}{ Reference } \\
\hline & $P \leq 0.001$ & $P=0.002$ & $P=0.15$ & \\
\hline
\end{tabular}

Data reported as difference in HbAlc (95\% confidence intervals).

${ }^{\mathrm{a}}$ Unadjusted.

${ }^{\mathrm{b}}$ Adjusted for baseline measures of average systolic and diastolic blood pressure and for Cockcroft-Gault estimated glomerular filtration rate.

${ }^{\mathrm{c}}$ Adjusted for the confounders in model 2, plus ethnicity, sex, age, and BMI.

TABLE 4: Linear regression to determine the difference in fasting blood across $\mathrm{K}^{+}$quartiles.

\begin{tabular}{|c|c|c|c|c|}
\hline \multirow{2}{*}{ Models } & \multicolumn{4}{|c|}{$\mathrm{K}^{+}$quartiles } \\
\hline & $<4.0 \mathrm{mmol} / \mathrm{L}$ & $4.0-4.2 \mathrm{mmol} / \mathrm{L}$ & $4.3-4.4 \mathrm{mmol} / \mathrm{L}$ & $\geq 4.5 \mathrm{mmol} / \mathrm{L}$ \\
\hline \multirow{2}{*}{ Model $1^{\mathrm{a}}$} & $-0.01(-0.07$ to 0.05$)$ & $-0.04(-0.09$ to 0.02$)$ & $-0.06(-0.12$ to 0.006$)$ & \multirow{2}{*}{ Reference } \\
\hline & $P=0.76$ & $P=0.19$ & $P=0.08$ & \\
\hline \multirow{2}{*}{ Model $2^{b}$} & $-0.02(-0.08$ to 0.04$)$ & $-0.05(-0.11$ to 0.12$)$ & $-0.05(-0.11$ to 0.01$)$ & \multirow{2}{*}{ Reference } \\
\hline & $P=0.43$ & $P=0.08$ & $P=0.12$ & \\
\hline \multirow{2}{*}{ Model $3^{\mathrm{c}}$} & $0.01(-0.05$ to 0.07$)$ & $-0.001(-0.05$ to 0.05$)$ & $-0.02(-0.08$ to 0.04$)$ & \multirow{2}{*}{ Reference } \\
\hline & $P=0.75$ & $P=0.97$ & $P=0.49$ & \\
\hline
\end{tabular}

Data reported as difference in fasting blood glucose (95\% confidence intervals).

${ }^{\mathrm{a}}$ Unadjusted.

${ }^{\mathrm{b}}$ Adjusted for baseline measures of average systolic and diastolic blood pressure and for Cockcroft-Gault estimated glomerular filtration rate.

${ }^{c}$ Adjusted for the confounders in model 2, plus ethnicity, sex, age, and BMI.

Melanie J. Davies, and Lauren M. Quinn developed the potassium analysis protocol. Danielle $\mathrm{H}$. Bodicoat conducted all statistical analyses. Patrice Carter and Danielle H. Bodicoat wrote the initial paper; Melanie J. Davies, Kamlesh Khunti, David Webb, Francesco Zaccardi, and Lauren M. Quinn contributed to the final paper.

\section{Acknowledgments}

The authors are indebted to the general practices participating in the study together with the entire Leicester diabetes research team. The research was supported by The National Institute for Health Research Collaboration for Leadership in Applied Health Research and Care, East Midlands (NIHR CLAHRC, EM), the Leicester Clinical Trials Unit and the NIHR Leicester-Loughborough Diet, Lifestyle and Physical Activity Biomedical Research Unit which is a partnership between University Hospitals of Leicester NHS Trust, Loughborough University, and the University of Leicester. The views expressed are those of the authors and not necessarily those of the NHS, the NIHR, or the Department of Health.

\section{References}

[1] The Global Burden, 2015, http://www.idf.org/diabetesatlas/5e/ the-global-burden.

[2] F. J. He and G. A. MacGregor, "Beneficial effects of potassium on human health," Physiologia Plantarum, vol. 133, no. 4, pp. 725$735,2008$.
[3] R. Chatterjee, L. A. Colangelo, H. C. Yeh et al., "Potassium intake and risk of incident type 2 diabetes mellitus: the Coronary Artery Risk Development in Young Adults (CARDIA) Study," Diabetologia, vol. 55, no. 5, pp. 1295-1303, 2012.

[4] Y. Heianza, S. Hara, Y. Arase et al., "Low serum potassium levels and risk of type 2 diabetes: the Toranomon Hospital Health Management Centre Study 1 (TOPICS 1)," Diabetologia, vol. 54, no. 4, pp. 762-766, 2011.

[5] R. Chatterjee, H.-C. Yeh, T. Shafi et al., "Serum and dietary potassium and risk of incident type 2 diabetes mellitus. The Atherosclerosis Risk in Communities (ARIC) study," Archives of Internal Medicine, vol. 170, no. 19, pp. 1745-1751, 2010.

[6] C. Meisinger, D. Stöckl, I. M. Rückert et al., "Serum potassium is associated with prediabetes and newly diagnosed diabetes in hypertensive adults from the general population: the KORA F4Study," Diabetologia, vol. 56, no. 3, pp. 484-491, 2013.

[7] D. R. Webb, K. Khunti, B. Srinivasan et al., "Rationale and design of the ADDITION-Leicester study, a systematic screening programme and Randomised Controlled Trial of multifactorial cardiovascular risk intervention in people with Type 2 Diabetes Mellitus detected by screening," Trials, vol. 11, article $16,2010$.

[8] WHO, "Definition and diagnosis of diabetes mellitus and intermediate hyperglycaemia," January 2015, http://www.who.int/ diabetes/publications/en/.

[9] M. A. Sperling, "ATP-sensitive potassium channels-neonatal diabetes mellitus and beyond," The New England Journal of Medicine, vol. 355, no. 5, pp. 507-510, 2006. 


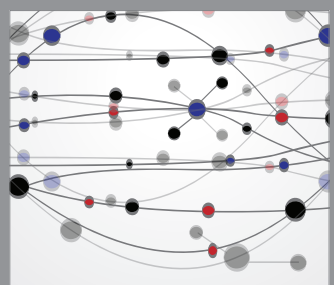

The Scientific World Journal
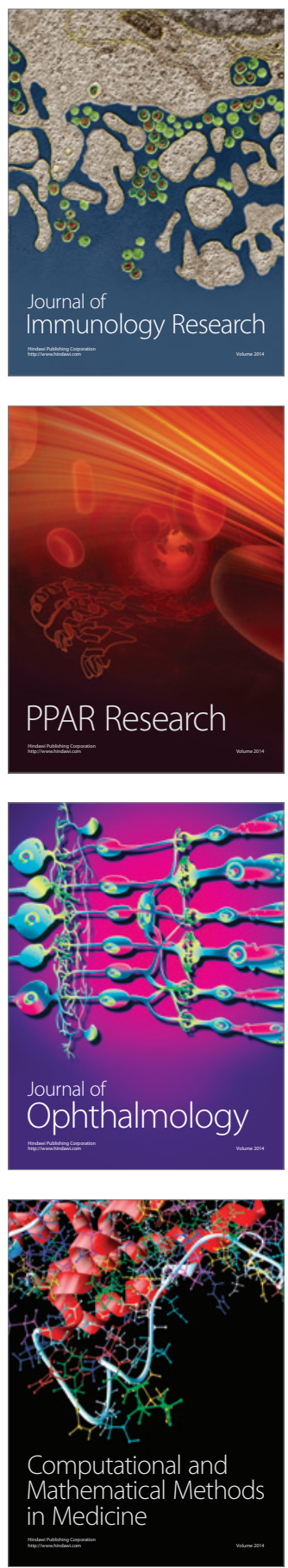

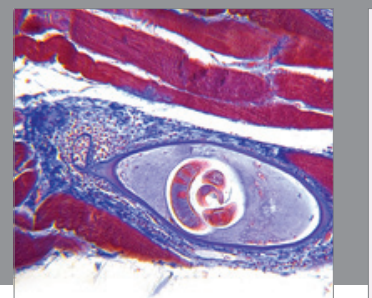

Gastroenterology

Research and Practice
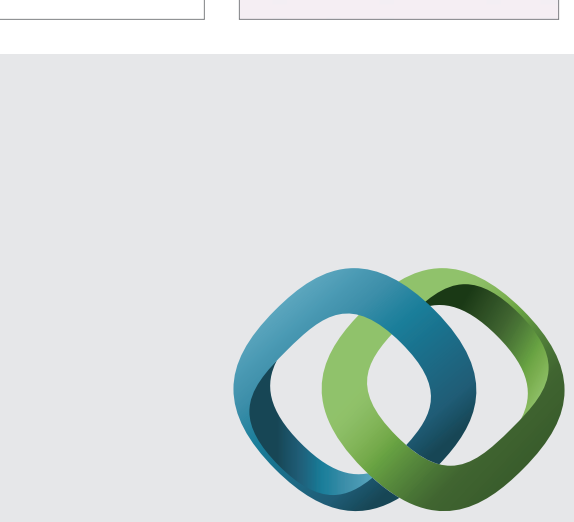

\section{Hindawi}

Submit your manuscripts at

http://www.hindawi.com
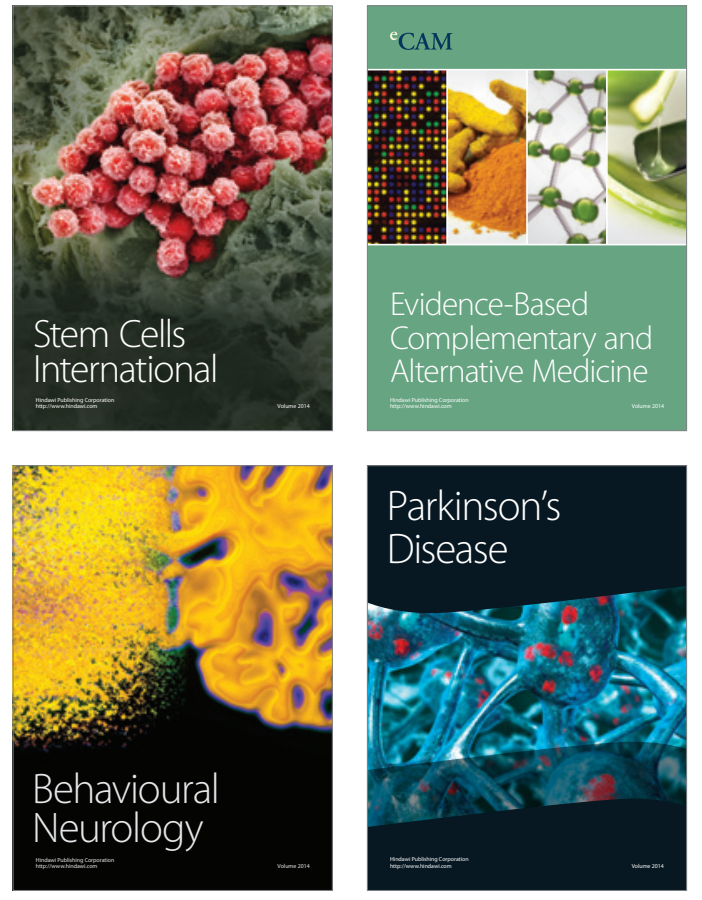
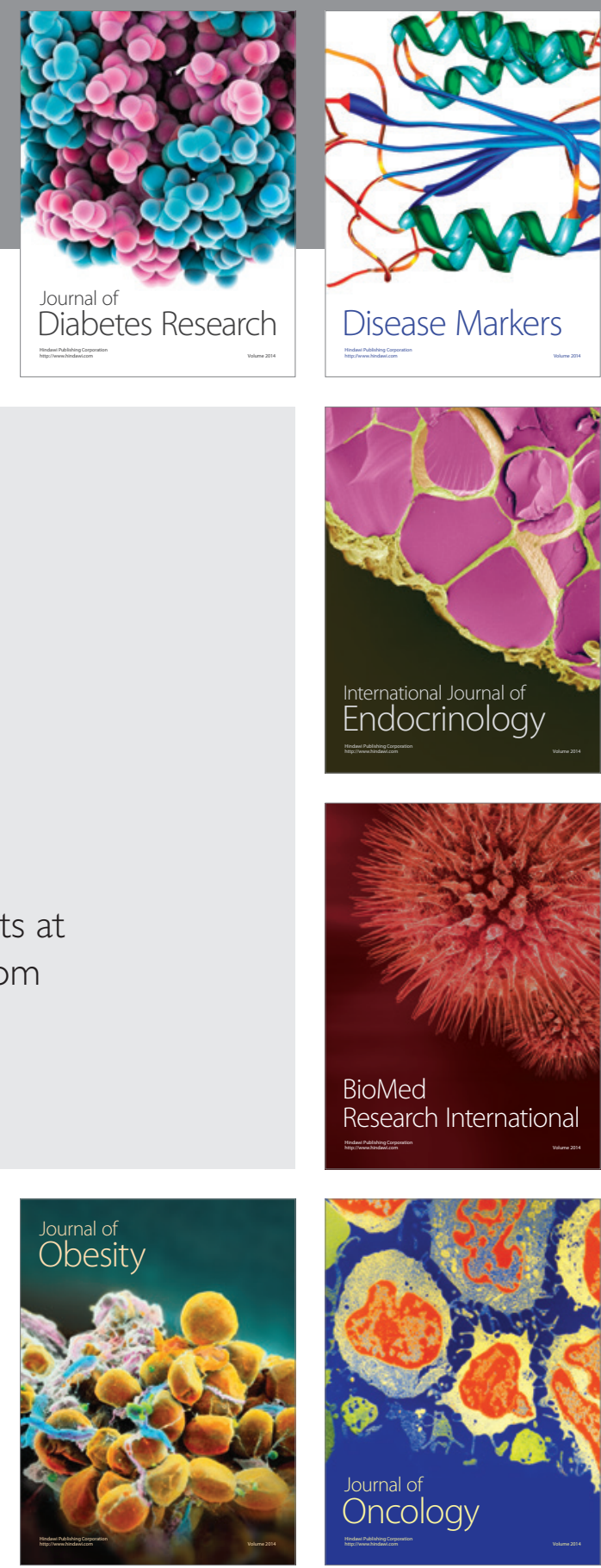

Disease Markers
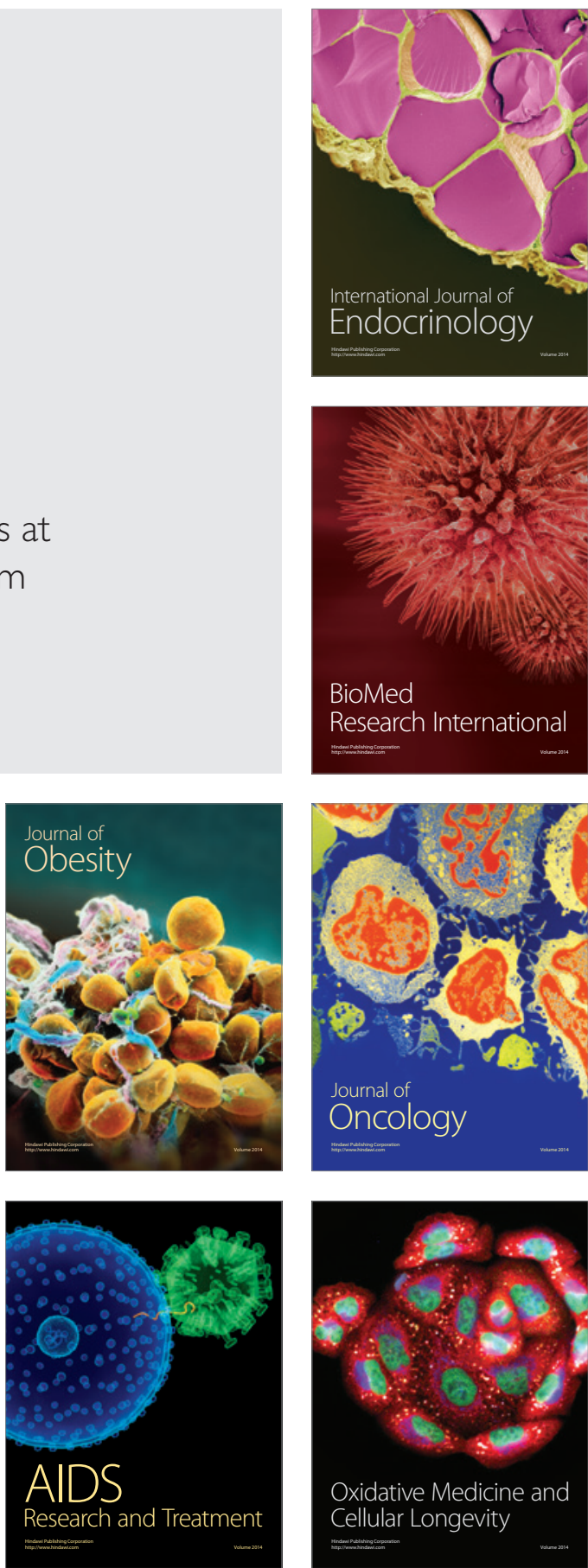